\title{
0 Design Como Objeto de Memória
}

\author{
Cultural Heritage and Building of Identities
}

por Nelson Martins de Almeida Netto e Silvia Sell Duarte Pillotto

RESUMO

Por meio da análise e imbricamento de identidade, memória e design, embasada no acesso a respeitáveis fontes bibliográficas, pode-se identificar, não raras vezes, nexo etiológico formal entre o design dos objetos e a história. Aludido vínculo enseja a formação de um patrimônio cultural, este servirá de referência às construções de identidade dos sujeitos envolvidos. Em tal contexto, não há a mínima dúvida, o design constitui um dos fatores contemporâneos de transformações, logo elemento promotor de construções identitárias. A lógica desenvolvida leva a concluir, os objetos de memória, por meio de seu design, propiciam compreensão das origens e percepção da evolução dos indivíduos em relação a práticas funcionais e comportamentais da vida em sociedade.

Palavras-chaves: Identidade, Memória e Design.

\section{ABSTRACT}

Through analysis and relation among identity, memory and design, based on reputable literature sources, we can frequently identify a formal etiological link between the design of objects and history. Alluded to the relationship erects cultural heritage and due reference constructs identity of the persons involved. In such a clear context, the relations of design come as contemporary transformations, and so, as an element that promotes identity constructions. The logic developed leads to the conclusion that the objects of memory through design provide understanding of the origins and perception of the evolution of individuals in relation to functional practices and behavior of a life in society.

Keywords: Identity, Memory and Design. 


\section{o Design Como Objeto de Memória}

\section{Introdução}

Transformações integram o processo de vida de diferentes seres. 0 decurso do tempo permite entrever as variações advindas desse processo evolutivo - de forma imediata ou à distância. Ainda que os impactos de tais transformações possam se ostentar imperceptíveis, a mutabilidade prossegue seu curso inconsciente.

Logo, não desborda do razoável situar o design entre outros fatores contemporâneos das já mencionadas transformações - hábil, portanto, a influir fortemente nas construções identitárias. Ademais, a análise retrospectiva também autoriza afirmar: o reagente em destaque (Design) permite sua manipulação para a solução de problemas individuais ou de grandes massas, por meio de inesgotável desenvolvimento e fabricação de produtos.

A atividade mercadológica de compra e descarte de produtos viabiliza as transformações supracitadas; cabe asseverar, em consequência destas, memórias são construídas. Porém substituição de produto já existente ou introdução de produto inédito não se faz por autopoiese: imprescindiveis, a esse desiderato, pesquisas e experimentações por profissionais habilitados.

De tudo ressumam as seguintes questões: o design dos objetos guarda nexo formal etiológico com a história, edifica-se como patrimônio cultural, constitui referência às construções de identidades de sujeitos?

\section{Construções de Identidade}

Seja qual for a abrangência interdisciplinar do tema (Semiótica Greimasiana e Psicanálise Freudiana), interessam aqui as identificações percebidas entre os indivíduos e seus referenciais.

De acordo com doutrina balizada de Beividas; Ravanello (2006), a identidade se constrói pelo 'princípio de permanência'. Aludido princípio garante ao indivíduo a continuação do seu 'ser', independentemente de transformações resultantes de sua existência e competências. Sob esta ótica linguística, determinados elementos, sustentadores da construção de identidade, como o nome próprio, estão relacionados aos procedimentos de anaforização.

A contrário sensu, identificação deve ser entendida como procedimento de interpretação: trata-se da operação pela qual o enunciatário assume o universo do personagem, quer dizer, identifica-se com a figura fictícia da obra.

Releva, contudo, o ponto de vista de Gonçalves (2005): a construção do "eu" pressupõe articulação entre os aspectos psicológicos e biológicos de um indivíduo com os seus aspectos sociológicos. A seu juízo, na atualidade o movimento necessário à construção de identidade, compreendida como troca de sinais, sucumbiu devido às alterações causadas pela presença ostensiva das novas mídias. Tornam-se mais fluidas as relações de 


\section{o Design Como Objeto de Memória}

construção identitária.

Hall (2006, p.10) distingue a identidade em três concepções de sujeitos: 0 "sujeito do Iluminismo", o "sujeito sociológico" e o "sujeito pós-moderno". Destes, cada qual revela relações com períodos e acepções distintas. 0 sujeito do iluminismo apresenta-se como um indivíduo centrado, dotado da razão, consciência e ação, cuja identidade está sincronizada ao nascimento e evolui em seu cerne sem se alterar, durante os anos. 0 sujeito sociológico traz em si toda a complexidade do mundo moderno, percebe a necessidade das relações com os outros indivíduos e a incapacidade de viver apenas no eucentrismo e na autossuficiência. Todavia, tem seu caráter construído por outros sujeitos, responsáveis por criar e mediar os valores e as figuras simbólicas, ele recebe destes todas as informações de como ser e representar-se dentro das expectativas e padrões de costumes. 0 sujeito pós-moderno, segundo Hall (2006), deixa de ser estável e previsível. Neste sujeito a identidade mostra-se tão mutável quanto são multiplicados os sistemas de significação cultural. Significa dizer: ao alterar-se o entorno ou o grupo de interação, a identidade muda. A percepção de identidade única, fundida desde 0 nascimento, e forjada na infância, trata-se de fantasia que cada indivíduo cria, visando sentir-se seguro de si e compreender sua representação principal.

Isso posto, a identidade pode ser percebida como representação teatral de cada indivíduo, e este papel pode variar dependendo do jogo social do qual participa. Um mesmo indivíduo pode representar ser militar quando fardado ou no batalhão, pai em sua casa, religioso em seu templo, de esquerda ou direita nas eleições e assim por diante.

A construção de identidade está estruturada nas memórias, as quais trazem à tona a relação do "quem sou" a partir do "quem foram". As relações de identidade inicialmente construídas e transferidas dentro dos grupos familiares, por meio das memórias, representam denominações de memória genealógica e familiar fundamentadas por Candau (2011), aludindo-se ao jogo da memória e da identidade, inerentes a qualquer cultura. Por conseguinte, o desejo da manutenção da memória e sua concretização através da continuidade das identidades familiares. Candau (2011) aponta ser curta a memória familiar, quer dizer, um indivíduo será lembrado por, no máximo, três gerações. A vontade de compartilhar as lembranças se apresenta em nível de metamemória, intrincada em cada descendente, e a sua importância está ancorada na organização da identidade do sujeito, seja pela repetição de comportamentos e rituais, pela conservação coletiva de saberes e referenciais ou ainda pela conservação de recordações familiares.

Bauman (2009) liga a existência da identidade diretamente ao contato com diferentes comunidades, pois o intercâmbio de várias ideias e as considerações necessárias à convivência, coexistência e tomada de decisões, relacionadas a cada grupo distinto, edifica os diferentes perfis identitários.

Cabe dizer: 0 credo nas ideias constrói os perfis, e a repetição delas faz a manutenção e, por vezes, as ressignifica, criando um ciclo de desenvolvimento da identidade. A percepção de inserção nestes ideais, cumprindo com os rituais deste grupo, será mais bem percebida a distância, quando em meio aos diferentes ou não pertencentes ao mesmo grupo, daí sucede a sensação de pertencimento. (BAUMAN, 2009)

No momento em que se apresentam as revisitações do passado glorioso de uma pá- 
tria, como os desfiles de 7 de setembro no Brasil ou 4 de julho nos Estados Unidos da América, são as lembranças de um grupo reconstruindo as identidades de todo um país. Estas representações estão presentes em todas as dimensões, de países inteiros a grupos folclóricos, exemplos disto são a Oktoberfest para Blumenau, o Carnaval para Rio de Janeiro e São Paulo ou o Festival do Boi de Parintins para o Pará. Tratam-se de manifestações compostas de pontos específicos da identidade de cada grupo cultural.

Conforme Candau (2011), um ponto crítico está em perceber não fazer mais sentido comemorar ou relembrar algumas situações, isto revela uma crise de identidade quando as datas comemorativas postas com intenção de reviver as glórias nacionais passam a representar apenas um momento de pausa laboral, sem dar-se o devido sentido. A recorrência anual destes movimentos deve trazer em si o reviver da situação original e ampliar a sensação de pertencimento.

Bauman (2009) desguarnece: um dos estigmas contemporâneos está em determinar a "minha identidade". Paradigmáticas estranhezas são causadas por pessoas portadoras de uma identidade autoimposta, construída e por vezes teatralizada, a exemplo das fruits girls ou harajuko girls e dos punks, apresentados imageticamente na figura 01.

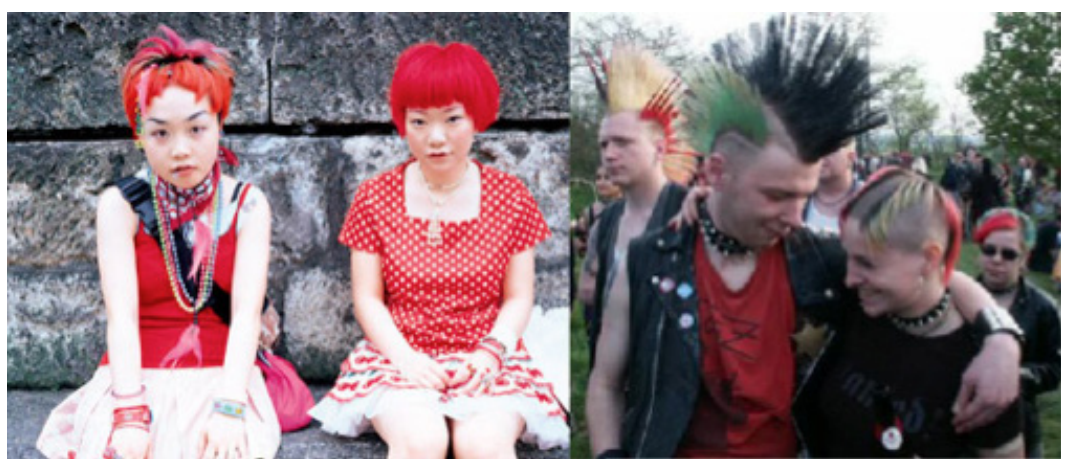

Figura 01: Fruit e Punks Fonte: NETTO, 2013

A sensação de deslocamento reflete da imposição de uma configuração não convencional de vestuário e comportamento. Para estes indivíduos se trata apenas de pele, cabelos e roupas; aos demais, não pertencentes destes grupos, significa apenas uma maneira diferente de representação.

Magalhães (2005) sustenta a identidade como resultado das trocas sociais, constrói e reconstrói-se a cada nova interação de um grupo de indivíduos com um novo grupo. Considera então a representação mutável, por vezes, instantânea, e por sua vez pode ser percebida tão instantaneamente ou não. Sua variação pode atingir uma rápida expressão suscitando as alterações corporais. Estes são aparentemente resultados da necessidade humana de apresentar e representar cada vez mais a sua autenticidade, 0

$1 \quad$ Fruits ou Harajuko Girls: adolescentes e jovens que criaram uma excêntrica subcultura baseada na reinvenção de elementos típicos japoneses misturados com elementos ocidentais e peças de segunda mão que resultaram em ousados e inesperados modos de se vestir; uma busca, talvez desesperada, por diferenciação individual em uma sociedade cada vez mais planificada e homogênea. (FASHIONBUBBLES, 2009) 


\section{o Design Como Objeto de Memória}

seu eu como indivíduo diferente dos demais.

A revolução do consumo apresenta-se como um dos elementos estruturadores da necessidade de construir uma individualidade/identidade claramente perceptível. Mccraken (2003) aduz ser de longa data esta dinâmica de mudanças estimuladas pelo consumo, um exemplo disto sustenta a teoria Trickle-down ${ }^{2}$, que aponta as construções de gênero e as mudanças sociais baseadas na moda. Como se houvesse uma força impulsionadora de mudanças, quando grupos sociais subordinados - na intenção de ascensão por imitação - adotam o vestuário de um grupo superior, este por sua vez muda novamente na intensão de manter a diferenciação.

Por volta do século XIX a sociedade e o consumo estavam intrinsicamente ligados em um contínuo processo de mudanças. Naquele momento surgiu o conceito da loja de departamentos, juntamente com os "estilos de vida de consumo" (MCCRAKEN, 2003). Citado princípio levanta ser a revolução do consumo responsável pelos recursos culturais necessários ao confronto do deslocamento cultural urdido pela revolução industrial.

Em tal caso percebem-se as mudanças cíclicas das sociedades, reconstruindo-se a cada momento - e em dadas vezes abandonando por completo - hábitos, costumes, objetos, entre outras coisas. Os motivadores das mudanças não fazem parte desta análise, mas sim os resultantes destas variações e, neste sentido, a preservação da história corresponde a uma das maneiras de se realizar esta preservação, trata-se da reserva organizada e sistemática de objetos de memória, de arte ou de uso cotidiano.

\subsection{Objetos de Memória}

Segundo a análise histórica de Nora (1993), simultaneamente ao desaparecimento da memória tradicional ressalta-se a necessidade de acumular vestígios da história. Os testemunhos podem ser documentos e objetos, compondo sinais tangíveis do já vivido. Situação esta oriunda da dinâmica da vida atual: quanto menos vivenciar-se a memória coletivamente, maior será a necessidade de sua preservação, em resposta, homens trazem para si a responsabilidade de fazê-lo.

Uma das maneiras utilizadas almejando a preservação da memória está presente na construção de coleções de objetos, como os museus. Adotam-se critérios promotores da organização dos objetos em um museu; conforme Magalhães (2005), estes são normalmente agrupados por similaridade, relacionando-os por período e material em que foram produzidos. Entretanto Scheiner (2006) atenta sobre a frequente construção de equívocos, isto ocorre na ânsia de se transmitir uma mensagem e pela aplicação de contextualizações puristas, onde se tenta recriar uma trajetória por meio de um ponto de vista centralizado.

Compreender as funções reais ou atribuídas a cada objeto faz parte do processo de estudo cultural. Redobra-se a relevância em perceber: os objetos não apenas demarcam ou expressam posições sociais e identidades, mas também estabelecem ou instituem a maneira pela qual os indivíduos e seus grupos sociais experimentam as identidades e

2 Trickle-down: Mais informações em, MCCRAKEN, 2003, p.123. 


\section{o Design Como Objeto de Memória}

OS status. (GONÇALVES, 2007).

A título de exemplo, analisa-se a evolução da plaina de mão, representada na figura 02.

\section{EVOLUÇÃO TECNOLÓGICA}
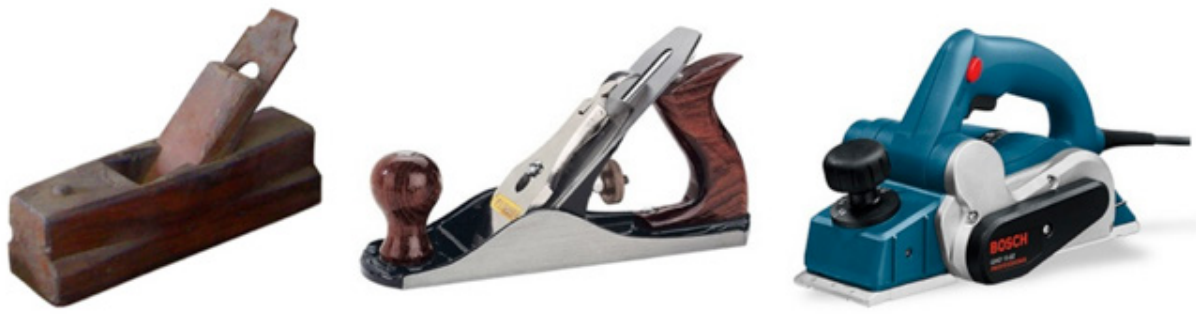

Figura 02: Evolução da plaina de mão Fonte: 0 autor

Durante o uso de uma ferramenta, o novo usuário pode não conhecer a origem daquele equipamento; no entanto, a possibilidade de perceber a evolução da ferramenta e de analisar como era utilizada permite a construção de uma nova memória, regada da experiência da comparação entre ambas.

Esta ferramenta, por exemplo, destina-se a extrair lascas de madeira a fim de dar-lhe forma. Exemplares deste equipamento fizeram parte da bagagem dos imigrantes alemães colonizadores da região de Joinville, conforme mostra a vitrine dos objetos da bagagem do imigrante, presente no acervo permanente do Museu Nacional da Imigração e Colonização - MNIC, apresentada na figura 02 .

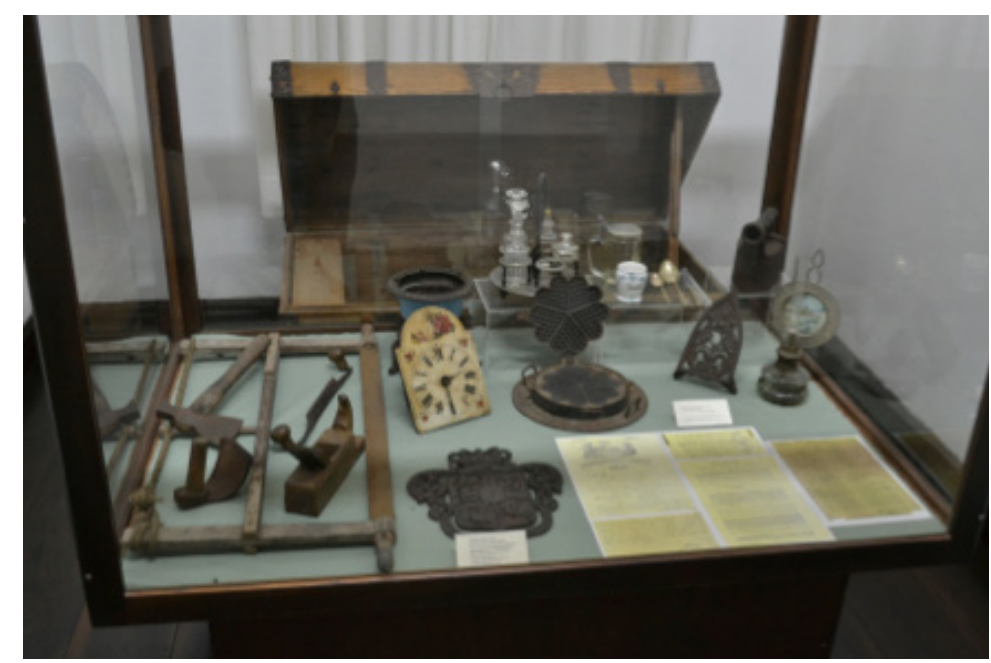

Figura 02: Vitrine objetos da bagagem do imigrante Fonte: NETTO, 2013

Cabe ressaltar: os "objetos de memória" aqui apresentados se referem aos objetos 


\section{Design Como Objeto de Memória}

museais, aos quais atribuídos valores simbólicos, estéticos e culturais. 0 patrimônio, constituído por ideias e objetos com os quais as sociedades afirmam as suas diferenças perante os outros, hoje fundamenta a celebração da memória para a construção/ reconstrução das identidades. (MAGALHÃES, 2005)

Referido conceito ratifica o formato e as características físico/construtivas de cada objeto, são os primeiros elementos percebidos em uma visitação. Por vezes a sua função primordial não se destaca, isto devido à situação de exposição a qual estão submetidos. Porém quando o objeto adormece sua função primordial, passa a construir uma nova, a de ser um produto de decoração ou referência de um período ou época.

\section{Design}

De Moraes (2008) assenta: o Design atual resulta da trajetória histórica, esta iniciou-se com a revolução industrial em meados do século XVIII, durante o processo de mecanização das indústrias têxteis, de cerâmicas, utensílios metálicos e objetos de vidro. Neste momento ocorreram as primeiras experiências de reprodução em série. A divisão entre projeto e produção oportunizou o aperfeiçoamento de ambas as etapas desta tarefa, 0 fabricante especializou-se em sua função de reproduzir produtos e 0 idealizador aperfeiçoou as técnicas de projetação, dando origem ao designer.

A relação com a indústria e a produção em série guiou a evolução dos produtos de artesãos, compreendidos naquele período como arte. Desenvolve-se um perfil sistematizado e metodológico do produto, o qual, ao longo da história transforma os conceitos além de, consequentemente, sua forma de apresentação. Alicerçado ao liame exposto por De Moraes (2008), sustenta-se a existência etérea do design.

Liga-se então o progresso da produção em série à utilização de diversos materiais, como madeira e metais, estes influenciadores da velocidade produtiva e facilitadores da padronização das formas e do acabamento dos produtos. A aplicação destas teorias na indústria da época promoveu uma revolução na percepção do significado de design, este passou a representar a evolução da produção industrial.

A forma, a função ou a emoção inerentes aos produtos advém das relações elaboradas pelos designers durante o processo de desenvolvimento. Bürdek (2010) aponta: o perfil do design das décadas de 1960 e 1970 foi intimamente influenciado por temas sociais. Sobre o mesmo período, De Moraes (2008, p.46) afirma ter sido especialmente significativo para a cultura do design, sendo um dos principais elementos de influência a "[...] vanguarda supertecnológica inglesa do Archigran, dos pintores pop americanos, dos grupos da nova vanguarda artística, visiva e literária.".

Esta influência só pode ser percebida hoje pelo resgate dos objetos unido à análise das narrativas da época. 0 conjunto de fatores, produto-design-memória, narra cada período dentro de um contexto específico. Por conseguinte, o design emociona e faz as pessoas consumirem produtos, mas também as estimula a visitar locais que proporcionem a compreensão da evolução dos produtos, como os museus de objetos. 
A percepção da aplicabilidade e usabilidade de produtos antigos pode auxiliar a compreensão das formas e da maneira de uso dos produtos atuais. Uma das tendências do design atual aponta à retomada das formas antigas, ou até mesmo o retorno de produtos com a forma original de 20,30 ou mais anos atrás. Bem figura esta hipótese o jogo eletrônico Gênius da marca Estrela, evidenciado na figura 03, lançado em 1980 quando obteve sucesso de vendas, e em 2012, ano do septuagésimo quinto aniversário da marca, foi relançado exatamente igual a 1980.

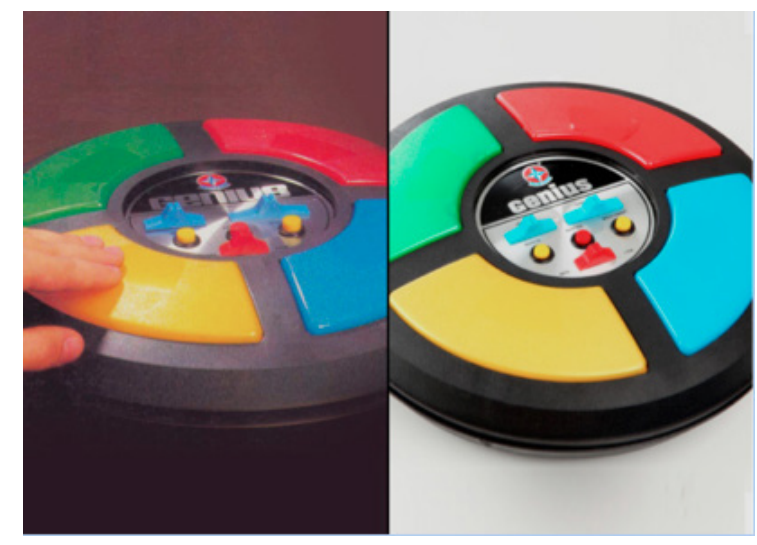

Figura 03: Jogo Gênius 1980 - 2012

Fonte: ARGEMON, 2012

Argemon (2012) manifesta: os bonecos do Forte Apache, outro brinquedo famoso no Brasil na década de 1980, serão relançados em 2013 quando a Gulliver, sua fabricante, completa 50 anos. A popularidade do tema faroeste está em baixa hoje em dia, "[...] mas os pais gostam de ver seus filhos brincando com os mesmos objetos de quando eram pequenos". (LAVIN apud ARGAMEON, 2012)

Visto que o gosto pelo antigo reforça a intenção de uso de um determinado produto confirma ocorrer a ativação da memória pela emoção de revê-lo -, esta sensação se assemelha ao estupor de rever um objeto similar no museu, apesar de o objeto do museu provir de um produto que perdeu a sua função prática e foi inserido em um espaço de contextualização, representatividade e simbolismos, o seu design não mudou.

\subsection{Produto Como Objeto de Memória}

Normalmente o produto resulta imediatamente de um processo, mas em se tratando de design, os conceitos vão além. Cada produto está cercado de funções, resultantes de estudos de mercado, usabilidade e processos de fabricação. Gomes Filho (2006) conceitua produtos como sendo quaisquer objetos tridimensionais fabricados - indiferentes a sua composição, esta podendo ser simples -, configurados por poucas peças e partes, ou sistêmicos, resultantes de processos industriais complexos, compostos por um número maior de peças e partes. Em se tratando de design, um dos conceitos fundamentais do 


\section{Design Como Objeto de Memória}

desenvolvimento de produtos ocorre na relação estabelecida entre Homem e objeto.

Os fundamentos antropológicos de McCraken (2003) mostram ser a evolução constante dos processos industriais e os avanços tecnológicos incorporados a técnicas de marketing - associação de apelos estéticos, culturais e sexuais aos produtos - responsáveis por acelerar o ritmo do consumo atual. Ressalva-se ainda: este tipo de prática estrutura-se, desde o século XVIII, quando os produtores aprenderam a explorar dinâmicas sociais, como a competição por status, estimulando o consumo contínuo. Promove-se a compra e recompra para si próprio, estimuladas por uma necessidade construída pela obsolescência contínua dos produtos, o que causa profundos efeitos aos membros individuais da sociedade. (MCCRAKEN, 2003)

$\mathrm{Na}$ atualidade, percebe-se 0 impacto, por meio do interesse no modelo novo e o desapego ao produto usado. Consoante ao princípio sociológico e filosófico de Baudrillard (2012), o produto desatualizado passa a desvincular-se de sua função primordial e torna-se então um objeto.

Reitera-se ainda haver um estatuto particular dos objetos antigos, caracterizando-os como aqueles afastados de sua função primeira, estes culminam por representar em si toda uma época ou período, e desta forma assumem o papel de signo. Baudrillard (2012) descortina: nunca se possui um produto ou utensílio, pois este sempre remete ao mundo real, mas na verdade se possui a função, do objeto, relacionada ao indivíduo.

0 fundamento sociológico de Löbach (2006) diferencia produto de objeto; além da semântica, relaciona-os a três funções básicas: função prática, função estética e função simbólica. Toma ser a função prática responsável pela relação direta entre usuário e objeto, nela está a adequação do produto às necessidades fisiológicas e operacionais, como ergonomia, conforto, eficácia e resistência.

Já a função estética relaciona-se à percepção sensorial, nela o produto deve atender a atributos relativos à beleza e ao bem-estar, na relação entre usuário e produto. Caracteriza-se nesta função a responsabilidade de estabelecer a identificação entre produto e usuário. Segundo Comes Filho (2006), esta função trata do aspecto psicológico da percepção multissensorial, está sujeita a vários aspectos culturais do usuário, ela depende do repertório, da vivência e da experimentação estética deste.

A função estética liga-se diretamente à função simbólica, sendo esta a mais complexa das três, devido a relacionar-se aos fatores socioculturais, econômicos e políticos, regra-se pela configuração e afirmação do estilo ou status do usuário. Löbach (2006) afirma que um objeto tem uma função simbólica quando este estabelece ligações com as experiências e sensações anteriores, do usuário.

Com a finalidade de compreender as funções primárias ou primordiais de um objeto, necessita-se entender os fatores motivadores de compra, utilização, armazenamento ou descartar os diferentes produtos. Em concordância com Baudrillard (2012), a obsolescência e a efemeridade são fatores motivadores do desuso ou descarte de objetos, isto é, a perda da eficácia na execução da função prática ou a desatualização das funções estética e simbólica. Na figura 04 tomam-se como exemplos 0 veículo automotor Volkswagem 1973 em contraposição ao seu sucessor, o modelo 2013, este com a mesma função prática de seu antecessor. Em suma, as variações entre os modelos são as fun- 
ções estética e simbólica, pois a função prática de transportar pessoas se repete em ambos.

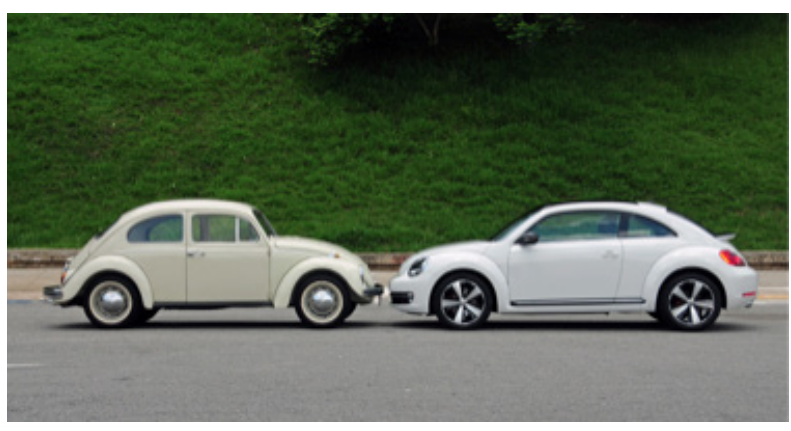

Figura 04: Fusca 1973 x Fusca 2013

Fonte: UOL, 2013

Apesar da diferença de idade entre os objetos, ambos com funções estéticas e simbólicas, a interpretação e a representação, porém, de cada função advinda deles é muito diferente. Um Fusca 1973 em seu ano de lançamento teve a mesma função estética do seu exemplar 2013 em seu lançamento, já a função simbólica, no entanto, mudou. Em 1973 o fusca era um produto popular feito para a família, já o modelo atual configura-se em um veículo mais suntuoso. Pode-se entender então que, ao se possuir um Fusca 1973 em 2013, representa-se um tipo de status diferente de ter um Fusca 2013 em 2013, e também, em ambas as situações, apenas a função simbólica se ressalta.

0 fator emocional construído define a escolha entre um ou outro objeto, o design no primeiro modelo pode relacionar-se apenas com forma, função, materiais, custo e possibilidade de produção, mas o modelo atual retoma as formas básicas do antigo, remetendo aos valores já consolidados, o que reativa a memória dos usuários.

A utilização de objetos como ferramentas, instrumentos e acessórios cotidianos faz parte da formação do ser humano e da construção da sociedade como um todo. Norman (2008) bisa: os objetos ressaltam memórias ou histórias originárias de experiências vividas em seu uso, esta ligação pessoal torna uma coisa, como um carro ou um relógio, tão importante para um indivíduo.

A reatividade entre homem objeto acontece pelo contato, físico ou visual, resultando em emoções. Norman (2008) evidencia existirem três níveis de processamento emocional, o visceral, o comportamental e o reflexivo. Todos os níveis se caracterizam como resultado das origens biológicas do cérebro e formam o conjunto de controle do ser humano. 0 visceral está como o controle automático, responsável por ações como amarrar um tênis sem olhar. 0 comportamental controla as ações cotidianas, enquanto as análises e contemplações são responsabilidade do processamento reflexivo.

0 imbricamento destes processamentos resulta na sensação, quando se vê ou revê algo, como o estupor de Canevacci (2011), em que a emoção causada em rever um objeto resultará em uma série de processamentos. Sobre esta experiência Norman (2008) afirma, num primeiro momento, o processamento visceral responderá com prazer ao 


\section{Design Como Objeto de Memória}

rever 0 objeto, em seguida o reflexivo fará uma pesquisa na memória trazendo à tona as experiências vividas com aquele objeto, sejam elas positivas ou negativas. Ao mesmo tempo, a mente realiza o processo de reflexão, ponderando acerca do passado, presente e considerando um possível futuro.

Nos apontamentos de Borges (2011), na mudança de padrões de vida causada pelo design devem ser considerados os fatores de conexão emocional, criados entre os usuários e seus objetos; quanto melhores os resultados de uso, mais os objetos são preservados e mantidos. Esta experiência entre indivíduo e objetos está ligada aos momentos da vida, elas podem ser boas ou ruins, cabe à percepção diferenciá-las. As reações humanas, frente a objetos, são as mais diversas, segundo Normam (2006); isto ocorre, pois o sistema cognitivo, responsável pelo julgamento, e o sistema emocional são intimamente ligados, um reforçando as reações do outro.

Conforme Russo at Hekkert (2008), as pessoas amam usar produtos, aos quais se atribuem memórias afetivas e por este motivo servem de recordação destas memórias. Isto se relaciona com a ideia de valorizar simbolicamente um produto, associando-o ao passado. Objetos responsáveis por estimular, ou que fazem parte de uma lembrança ou memória afetiva, carregam em si a capacidade de reativar as memórias de um momento, pessoa querida ou época, estas relativas aos seus usos anteriores.

0 momento de nostalgia proporcionado por este tipo de experiência resulta das características do produto como objeto de memória. Em cada indivíduo o resultado difere, pois as memórias ressaltadas são particulares. 0 resultado das análises das memórias, somado ao momento experimentado pelo individuo, poderá interferir na percepção acerca do objeto e, desta maneira, influenciar a construção/reconstrução de identidade do indivíduo.

\section{Conclusões}

Configura-se edificante compreender parte dos processos de transformação cultural e perceber como os objetos através de seu design, apesar destes por vezes alheios à vontade dos indivíduos, influenciam nas construções de identidade. Perceber que estas influências se apresentam ligadas às transformações culturais, políticas e econômicas ocorridas na sociedade estão em parte apresentadas em museus de objetos.

A construção de identidade está ligada diretamente aos movimentos culturais, como afirma Magalhães (2005); a identidade resulta das trocas sociais e se constrói e reconstrói a cada nova interação de um grupo de indivíduos com um novo grupo. Compreendendo isto, podem-se perceber as mudanças cíclicas das sociedades, reconstruindo-se a cada momento, por vezes abandonando completamente hábitos, costumes, objetos, entre outras coisas.

Doravante fundamental entender que uma das formas de se preservar culturas, ou pelo menos a essência delas, está no reconhecimento do design do objeto como patrimônio cultural, constituindo-se num dos elementos de manutenção da memória. Conçalves (2009) traz a ideia de que se atribui o conceito de patrimônio aos mais variados elemen- 


\section{O Design Como Objeto de Memória}

tos culturais, arquitetônicos, históricos, artísticos, etnográficos, ecológicos, e genéticos. Cabe ainda lembrar as novas definições de patrimônios intangíveis, as quais tratam de tudo aquilo que significa algo para um grupo ou localidade, sendo capaz de representar este grupo ou local aos demais.

Cada objeto contém uma história, alicerçado em Russo at Hekkert (2008), certifica-se: as pessoas amam usar produtos aos quais se atribuem memórias afetivas e que por este motivo estimulam a recordação destas memórias. objetos que estimulam ou fazem parte de uma lembrança ou memória afetiva carregam em si a capacidade de reativar as memórias de um momento, pessoa querida ou época.

Aludindo-se a referidos conceitos, avista-se que o design dos objetos compõe uma relação direta com a história do objeto, visto que sua representatividade está pautada na memória de cada indivíduo. Neste viés edifica-se como objeto de memória e, por consequência, patrimônio cultural, visto tornar-se uma referência às construções e reconstrução de identidades dos sujeitos e sociedade. 


\section{o Design Como Objeto de Memória}

\section{Referências}

$>$ ARGEMON, Rafael. Brinquedos de outras décadas voltam a ser moda. Veja São Paulo. 14.dez.2012 . Disponível em: <http://vejasp.abril.com.br/materia/brinquedos-de-outras-decadas〉. Acesso em: 28 mar. 2013.

> BAUMAN, Zygmunt. Identidade. Rio de Janeiro: Zahar, 2009.

> BAUDRILLARD, Jean. 0 sistema dos objetos. 5 ed. São Paulo: Perspectiva, 2012.

> BEIVIDAS, Waldir; RAVANELLO, Tiago. Identidade e Identificação: Entre semiótica e psicanálise. in: Alfa-Revista de Linguística (ILCSE/UNESP), v. 50 São Paulo: Alfa, 2006, p.129 - 144. Disponível em: http://www.linguistica.fflch.usp.br/node/575 Acessado em: $11 / 06 / 2013$.

> BORGES, Adélia. Bienal Brasileira de Design 2010 Curitiba. Curitiba, PR : Centro de Design Paraná, 2011.

$>$ BÜRDEK, Bernhard E. História, Teoria e Prática do Design de Produtos. 2. ed. São Paulo: Blucher, 2010

$>$ CANDAU, Joel. Memória e identidade. Tradução: Maria Lencta Ferreira. São Paulo: Contexto, 2011.

$>$ CANEVACCl, Massimo. Palestra: Comunicação Museal. Aula inaugural do curso de Mestrado em Patrimônio Cultural e Sociedade - UNIVILLE, 2011.

> DE MORAES, Dijon. Limites do design. 3. ed. rev. e ampl. São Paulo: Studio Nobel, 2008.

> FASHIONBUBBLES, Tribos Urbanas - Comunidades de Sobrevivência Afetiva. Disponível em: http://www.fashionbubbles.com/comportamento/tribos-urbanas-comunidades-de-sobrevivencia-afetiva. Acessado em: 07/09/2012.

> GOMES FILH0, João. Design do objeto: bases conceituais : design do produto, design gráfico, design de moda, design de ambientes, design conceitual. São Paulo: Escrituras, 2006.

$>$ GONÇALVES, José Reginaldo S. Teorias antropológicas e objetos materiais. In: Antropologia dos objetos: coleções, museus e patrimônios. Rio de Janeiro: Departamento de Museus e Centros Culturais, 2007. p.13-43.

> GONÇALVES, Paula Vanessa Pires de Azevedo. Ser Punk: a narrativa de uma identidade jovem centrada no estilo e sua trajetória. Dissertação Mestrado em Educação - Área de Sociologia de Educação. Universidade de São Paulo. Faculdade de Educação, 2005.

> HALL, Stuart; Woodward, Kathryn. Identidade e diferença. A perspectiva dos estudos culturais. Tradução Tomas Tadeu da Silva. 2 ed. Petrópolis RJ: Vozes, 2006.

> LÖBACH, Bernd. Design industrial: bases para a configuração dos produtos industriais. Tradução: Freddy Van Camp. São Paulo: Editora, 2006. 


\section{O Design Como Objeto de Memória}

> MAGALHÃES, Fernando. Museus, patrimônio e identidade. Ritualidade, Educação, Conservação, Pesquisa, Exposição. Porto - PT: Profoedições, Lda./ Jornal a Página, 2005.

> MCCRAKEN, Grant. Cultura e consumo: novas abordagens ao caráter simbólico dos bens e das atividades de consumo. Rio de Janeiro: Mauad, 2003.

> NETTO, Nelson Martins de Almeida. Ressignificando memórias e identificações nos espaços museológicos: objetos, design, narrativas e interações. Dissertação (Mestrado em Patrimônio Cultural e Sociedade - Universidade da Região de Joinville) orientadora Dra Silvia Sell Duarte Pillotto - Joinville: UNIVILLE, 2013. 100 f. : il. ; $30 \mathrm{~cm}$.

> NORA, Pierre. Entre memória e história. A problemática dos lugares. Tradução: Yara Aun Khoury. in: Projeto história: Revista do Programa de Estudos P6s-Gl11duados em História e do Departamento de História da PUC-SP. Pontifícia Universidade · Cató1ica de São Paulo, SP -Brasil, 1993

$>$ NORMAN, Donald A. Design emocional: por que adoramos (ou detestamos) os objetos do dia-a-dia . Rio de Janeiro: Rocco, 2008.

> RUSSO, Beatriz; HEKKERT, Paul. Sobre amar um produto: os princípios fundamentais. In: MONT'ALVÃO, Claudia; DAMAZIO, Vera (Orgs.). Design, ergonomia e emoção. Rio de Janeiro: Mauad X/FAPERJ, 2008. p. 31-48. Disponível em: http://studiolab.ide.tudelft.nl/ manila/gems/russo/RussoHekkertFINAL.pdf Acessado em: 10/07/2013

> SCHEINER, Tereza Cristina. Museologia e interpretação da realidade: o discurso da história (texto provocativo) - UNIRI0, Brasil, 2006. Disponível em: 〈http://www.museoliniers. org.ar/museologia/ICOFOM_TerezaScheiner-br.pdf>. Acessado em: 23/02/2013.

> UOL. Fuscas 1973 x 2013. Disponível em: http://imguol.com/2012/12/11/vw-fuscas-1973X-2013-1355195747126_956x500.png. Acessado em: 18/03/2013. 
Nelson Martins de Almeida Netto, Possui graduação em Design Industrial pela Universidade do Vale do Itajaí (2003), Pós Graduação Lattu Sensu em propaganda e Marketing pela Universidade do Vale do Itajaí (2006), Mestrado em Patrimonio Cultural e Sociedade pela Universidade da Região de Joinville - UNIVILLE. Atua como Coordenador dos cursos de Design e Moda do Centro Universitário de Jaraguá do Sul desde 2008. É membro conselheiro do COMPHAAN de Jaraguá do Sul. Tem experiência na área de Desenho Industrial, com ênfase em Desenho de Produto, atuando principalmente nos seguintes temas: moda, design, projeto de produto, fotografia e suporte de vendas.

nelsonmanetto@gmail.com

Silvia Sell Duarte Pillotto, Pós-Doutora no Instituto Estudos da Criança - IEC na Universidade do MINHO - UMINHO, Braga/Portugal em 2007/2008. Doutora em Engenharia de Produção (Gestão da Qualidade) pela Universidade Federal de Santa Catarina - UFSC (2003); Mestre em Educação (Currículo) pela Universidade Federal do Paraná - UFPR (1997); Especialista em Fundamentos Estéticos para a Arte na Educação pela Faculdade de Artes do Paraná (1992); Graduada em Educação Artística - Habilitação Artes Plásticas pela Universidade para o Desenvolvimento do Estado de Santa Catarina - UDESC (1983) Professora titular nos cursos de Artes Visuais e Pedagogia na Universidade da Região de Joinville - UNIVILLE e nos Programas de Pós-Graduação - Mestrado em Educação e Patrimônio Cultural e Sociedade; Pesquisadora e coordenadora de Núcleo de Pesquisa, possui experiência nas áreas de Artes, Gestão, Currículo, Avaliação e Arte/Educação. Avaliadora do INEP, atua nos seguintes níveis da educação: educação superior e pós-graduação. Autora de vários livros publicados, desenvolve formação continuada e consultoria nas áreas citadas.

pillotto0@gmail.com 